\title{
Realising epitaxial growth of GaN on (001) diamond
}

\author{
G. W. G. van Dreumel, ${ }^{1}$ P. T. Tinnemans, ${ }^{1}$ A. A. J. van den Heuvel, ${ }^{1}$ T. Bohnen, ${ }^{1}$ \\ J. G. Buijnsters, ${ }^{1,2}$ J. J. ter Meulen, ${ }^{1}$ W. J. P. van Enckevort, ${ }^{1}$ P. R. Hageman, ${ }^{1, a)}$ \\ and E. Vlieg ${ }^{1}$ \\ ${ }^{1}$ IMM, Radboud University Nijmegen, Heijendaalseweg 135, 6525 AJ Nijmegen, The Netherlands \\ ${ }^{2}$ Department MTM, Katholieke Universiteit Leuven, Kasteelpark Arenberg 44, B-3001 Leuven, Belgium
}

(Received 22 March 2011; accepted 14 May 2011; published online 1 July 2011)

\begin{abstract}
By an extensive investigation of the principal growth parameters on the deposition process, we realized the epitaxial growth of crystalline wurtzite $\mathrm{GaN}$ thin films on single crystal (001) diamond substrates by metal organic chemical vapor deposition. From the influence of pressure, V/III ratio, and temperature, it was deduced that the growth process is determined by the mass-transport of gallium precursor material toward the substrate. The highest temperature yielded an improved epitaxial relationship between grown layer and substrate. X ray diffraction (XRD) pole figure analysis established the presence of two domains of epitaxial layers, namely (0001) $\langle 10 \overline{1} 0\rangle \mathrm{GaN} \|$ (001)[110] diamond and (0001) $\langle 10 \overline{1} 0\rangle \mathrm{GaN} \|(001)$ [11̄0] diamond, which are $90^{\circ}$ rotated with respect to each other. The presence of these domains is explained by the occurrence of areas of $(2 \times 1)$ and $(1 \times 2)$ surface reconstruction of the diamond substrate. When applying highly misoriented diamond substrates toward the [110] diamond direction, one of the growth domains is suppressed and highly epitaxial GaN on (001) diamond is realized. () 2011 American Institute of Physics. [doi:10.1063/1.3601351]
\end{abstract}

\section{INTRODUCTION}

GaN-based devices have a unique potential for highpower applications. Recently, this has been demonstrated once more for a GaInN laser diode with $100 \mathrm{~W}$ peak power, ${ }^{1}$ while $\mathrm{Wu}$ et al. $^{2}$ reported output powers for AlGaN/GaN high electron mobility transistors (HEMTs), which reached a density of $32.2 \mathrm{~W} \mathrm{~mm}^{-1}$. In theory, even higher power outputs are possible. However, currently, GaN devices are hindered to a large extent by self heating problems.

To minimize these specific thermal problems, it is vital to extract the heat from the active area in the GaN device. This can be achieved by using alternative substrates that have higher thermal conductivity than the traditional sapphire and silicon substrates applied for GaN growth. Diamond has, by far, the highest thermal conductivity that is known. ${ }^{3}$ Therefore, a layer of high thermal conducting diamond between the device and the cooling system can significantly lower the temperature in these high-power structures. The attachment of GaN films onto diamond substrates, acting as heat sinks, would thus be a good solution to increase the power range in which $\mathrm{GaN}$ devices can be operated.

For this reason, in the last years, an increased interest has risen in research targeting the integration of these two materials. Besides investigations on the adding of a diamond layer on existing GaN structures, ${ }^{4,5}$ this research involves bonding of GaN on CVD diamond ${ }^{6-8}$ and the application of siliconon-diamond substrates. ${ }^{9,10}$ Recently, GaN has been deposited directly on several types of diamond substrate, ${ }^{11-15}$ leading to the successful fabrication of an AlGaN/GaN HEMT on (111) single crystalline diamond by MBE. ${ }^{16}$ Although this diamond

\footnotetext{
a) Author to whom correspondence should be addressed. Electronic mail: P.Hageman@science.ru.nl.
}

(111) substrate offers a nice threefold symmetry as a template for the growth of hexagonal $\mathrm{GaN}$, it is much more difficult to obtain and process in comparison to (001) diamond. Therefore, the formation of high quality epitaxial GaN on (001) diamond by metal organic chemical vapor deposition (MOCVD) is investigated in these studies.

In previous work, while obtaining the best conditions for the nucleation of $\mathrm{GaN}$ on polished polycrystalline diamond, it was already shown that the low lateral growth rate of the annealed nucleation islands hinders the formation of a closed layer. ${ }^{12}$ Similar problems can be identified in other reports, such as in the MOCVD growth of GaN on nanocrystalline and (110) oriented diamond substrates, ${ }^{11,13}$ for the $c$-oriented AlN deposition on various diamond faces ${ }^{17,18}$ and the closely related GaN and AlN growth on silicon substrates. ${ }^{19,20}$ To overcome this problem of slow lateral growth rate, the influence of several major parameters in $\mathrm{GaN}$ growth, like reactor pressure, precursor flow, growth temperature, and substrate misorientation, on the growth rate are investigated. In this way, important information on the growth process of $\mathrm{GaN}$ on diamond is obtained.

\section{EXPERIMENTAL}

For this study, the substrates used are $3.0 \times 3.0 \mathrm{~mm}^{2}$ single crystalline CVD diamond substrates, acquired from Element Six, UK. According to the supplier's specifications, the substrates have a nominal (001) orientation with a maximum deviation of $3^{\circ}$. With profilometry, the substrates' roughness is determined at $\mathrm{R}_{a}=3.12 \mathrm{~nm}$. Prior to growth, each sample is cleaned in an ultrasonic bath with $\mathrm{NH}_{4} \mathrm{OH} /$ $\mathrm{H}_{2} \mathrm{O}_{2} / \mathrm{H}_{2} \mathrm{O}$ solution (1:1:5), subsequently followed by rinsing in $\mathrm{H}_{2} \mathrm{O}$ and ultrasonic treatment in $\mathrm{HCl} / \mathrm{H}_{2} \mathrm{O}_{2} / \mathrm{H}_{2} \mathrm{O}$ solution (1:1:5). Then, the sample is again rinsed in $\mathrm{H}_{2} \mathrm{O}$ and cleaned 
TABLE I. Overview of the samples grown in these studies on nominal (001) diamond substrates.

\begin{tabular}{lcccccc}
\hline \hline Sample & $\begin{array}{c}\text { Thickness } \\
\text { GaN film }(\mu \mathrm{m})\end{array}$ & $\begin{array}{c}\text { Press. } \\
(\mathrm{mbar})\end{array}$ & $\begin{array}{c}\mathrm{NH}_{3} \\
(\mathrm{mmol} / \mathrm{min})\end{array}$ & $\begin{array}{c}\text { TMG } \\
(\mu \mathrm{mol} / \mathrm{min})\end{array}$ & $\begin{array}{r}\text { V/III } \\
\text { ratio }\end{array}$ & $\begin{array}{c}\text { Temp. } \\
\left({ }^{\circ} \mathrm{C}\right)\end{array}$ \\
\hline $\mathrm{A}$ & 0.80 & 35 & 100 & 52.5 & 1870 & 1170 \\
$\mathrm{~B}$ & 0.78 & 20 & 100 & 52.5 & 1870 & 1170 \\
$\mathrm{C}$ & 0.07 & 500 & 100 & 52.5 & 1870 & 1170 \\
$\mathrm{D}$ & 0.85 & 35 & 68 & 52.5 & 1275 & 1170 \\
$\mathrm{E}$ & 0.58 & 35 & 132 & 52.5 & 2465 & 1170 \\
$\mathrm{~F}$ & 1.55 & 35 & 100 & 105.0 & 935 & 1170 \\
$\mathrm{G}$ & 0.82 & 35 & 100 & 52.5 & 1870 & 1140 \\
$\mathrm{H}$ & 0.85 & 35 & 100 & 52.5 & 1870 & 1185 \\
$\mathrm{I}$ & 0.86 & 35 & 100 & 52.5 & 1870 & 1215 \\
\hline \hline
\end{tabular}

in an ultrasonic bath with HF solution and, finally, 5 times rinsing in $\mathrm{H}_{2} \mathrm{O}$.

$\mathrm{GaN}$ growth is performed in an Aixtron AIX-200 RF MOCVD reactor using trimethylgallium (TMG), trimethylaluminum (TMA), and ammonia gas $\left(\mathrm{NH}_{3}\right)$ as precursors for $\mathrm{Ga}, \mathrm{Al}$, and $\mathrm{N}$, respectively. Hydrogen is used as a carrier gas throughout the whole growth process. The influence of growth parameters is compared with samples prepared with the settings used in our earlier study (sample A, in Table I). ${ }^{12}$

For all samples, the nucleation and annealing steps were identical. An AlN nucleation layer was deposited at $850^{\circ} \mathrm{C}$ in 2 mins while the pressure was maintained at 50 mbar. The flow rates for $\mathrm{NH}_{3}$ and TMA during nucleation were $1.0 \times 10^{-1} \mathrm{~mol} / \mathrm{min}$ and $1.08 \times 10^{-5} \mathrm{~mol} / \mathrm{min}$, respectively. ${ }^{13}$ Annealing was performed in $\mathrm{NH}_{3} / \mathrm{H}_{2}$ atmosphere under 50 mbar total pressure for $1 \mathrm{~min}$ at $1170^{\circ} \mathrm{C}$. The parameter values applied for the main layer growth are outlined in Table I. To ensure the effects of the different parameters on the GaN island growth can still be observed, the growth time for the main layer was kept constant at 20 mins, and the resulting thickness for each sample is listed in Table I too.

The morphology of the substrates and the as-grown surfaces was studied using scanning electron microscopy (SEM, Jeol JSM 6330 F), while a Renishaw $1000 \mu$-Raman spectrometer with an $\mathrm{Ar}$ ion laser at wavelength $\lambda=514.8$ $\mathrm{nm}$ and $20 \mathrm{~mW}$ power was used to investigate the samples in backscattering geometry at room temperature (RT). The layer thickness and roughness were measured using a Wijco NT-1100 optical profiler. X ray diffraction (XRD) pole figures of the layers were recorded with a high resolution Bruker D8 diffractometer setup using $\mathrm{Cu} \mathrm{K}_{\alpha}$ radiation $(\lambda=1.5418 \AA)$. Photoluminescence (PL) spectra of the layers were taken at $5 \mathrm{~K}$. The samples were excited by a continuous-wave $325 \mathrm{~nm} \mathrm{HeCd}$ laser with a power density of 30 $\mathrm{Wcm}^{-2}$. The spectra were resolved by a $1 \mathrm{~m}$ monochromator, which was equipped with a UV-enhanced CCD detector.

\section{INFLUENCE ON MORPHOLOGY}

\section{A. Pressure}

The influence of pressure in the reactor during the growth of GaN has been investigated frequently in the past and has been marked as an important parameter for MOCVD growth of $\mathrm{GaN}^{21}$ It determines, for instance, at which temperature the transition between 3D and 2D growth mode occurs. De Theije et al. ${ }^{22}$ found that an increasing pressure in the reactor decreases the transition temperature for growth of $\mathrm{GaN}$ on sapphire. Therefore, its influence has been tested first, and SEM images of the samples, presented in Fig. 1, show the most significant results. Sample A (middle) is the reference sample obtained after growth at 35 mbar reactor pressure, while on the left side is the sample prepared at 20 mbar reactor pressure (sample B). Where sample A shows an ordered layer with all crystals having a relatively constant height, sample B is disordered with GaN crystals grown on top of another. Furthermore, the shape of the crystals is not so well defined as the obvious hexagonal symmetry (the preferred (0001) orientation for epitaxial growth) observed in the reference sample. It appears this is caused by secondary nucleation of $\mathrm{GaN}$ during the growth of the main GaN layer and that decreasing the pressure in the reactor increases the rate of mass-transport so much that kinetically limited growth is observed. ${ }^{21}$

When increasing the pressure up to a total reactor pressure of 100 mbar, no changes are observed and samples are almost identical to the reference sample. At even higher pressures, the grown film becomes very thin (see Table I), and only a few big crystals on top of a layer with small flat a) Sample B, p = 20 mbar

b) Sample A, p = 35 mbar

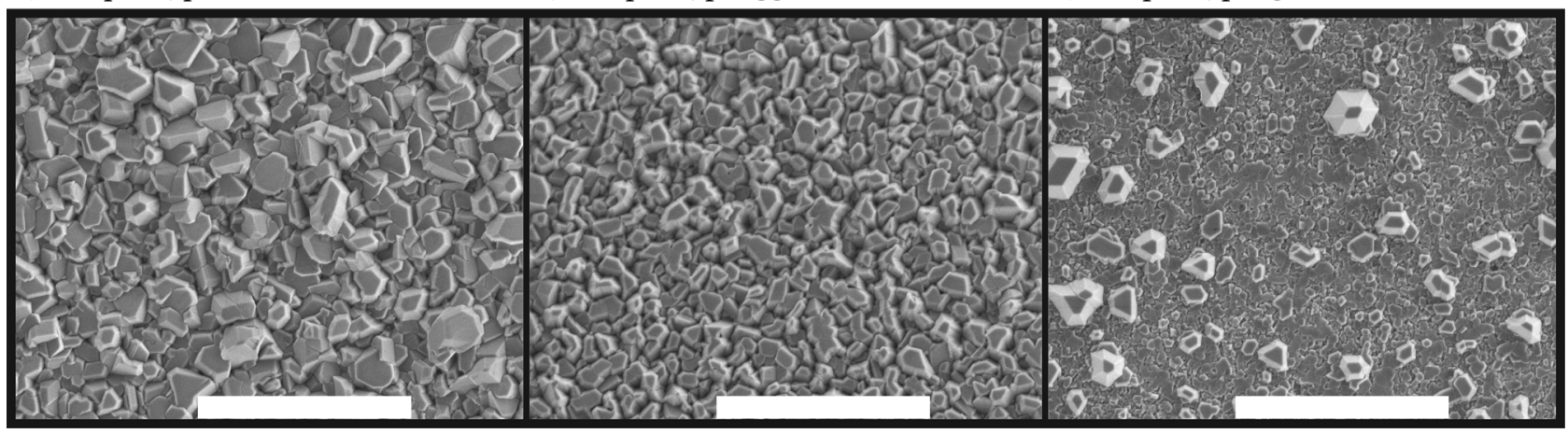

FIG. 1. SEM images showing the results of the change in reactor pressure during the main GaN layer growth, with increasing pressure from left to right: a) sample B prepared under 20 mbar pressure, b) the reference sample A prepared under 35 mbar, and c) sample $\mathrm{C}$ after the growth with 500 mbar reactor pressure. The scale bars represent $5 \mu \mathrm{m}$. 


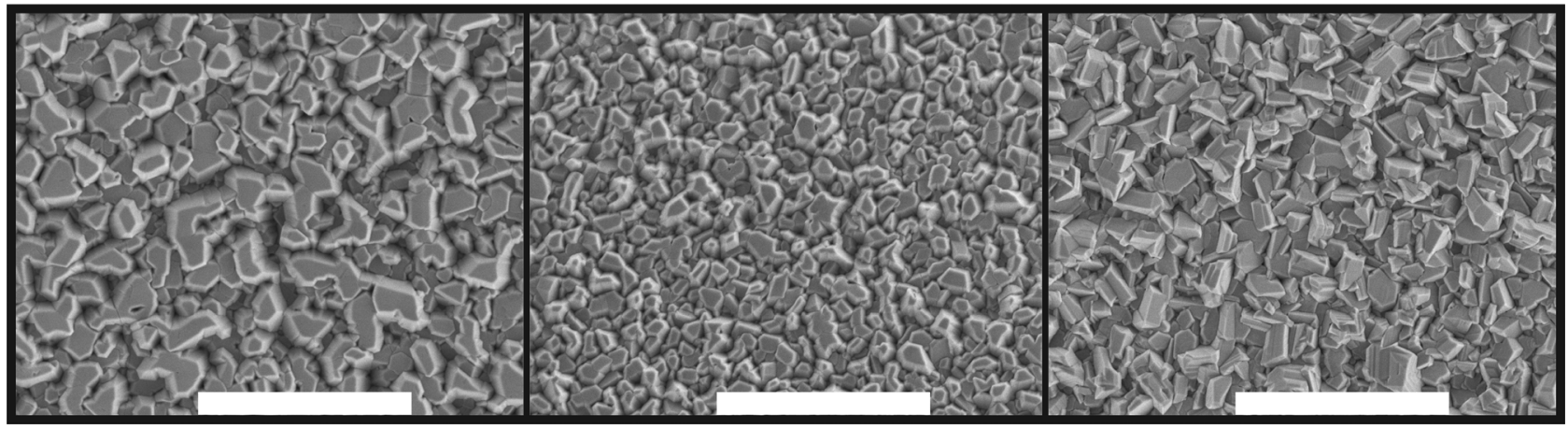

FIG. 2. SEM images taken from the series in V/III-ratio with increasing $\mathrm{NH}_{3}$ flow: a) sample $\mathrm{D}$ grown with $68 \mu \mathrm{mol} / \mathrm{min} \mathrm{NH} 3(\mathrm{~V} / \mathrm{III}=1275)$, b) the reference sample $\mathrm{A}\left(100 \mu \mathrm{mol} / \mathrm{min} \mathrm{NH}_{3}, \mathrm{~V} / \mathrm{III}=1870\right)$, and c) sample $\mathrm{E}$, grown with $132 \mu \mathrm{mol} / \mathrm{min} \mathrm{NH}_{3}(\mathrm{~V} / \mathrm{III}=2465)$. The scale bars represent $5 \mu \mathrm{m}$.

islands is observed. Sample C (Fig. 1(c)) is a typical example obtained at 500 mbar reactor pressure. As hydrogen is the carrier gas during MOCVD growth, it is essential to consider the reaction with $\mathrm{GaN}$, certainly at temperatures around $1170^{\circ} \mathrm{C}$. It decomposes $\mathrm{GaN}$ into volatile products via the following reactions: $:^{5,23}$

$$
\begin{aligned}
2 N_{(\text {surface })}+3 H_{2}(g) & \rightleftharpoons 2 \mathrm{NH}_{3}(g), \\
2 G a_{(\text {surface })}+H_{2}(g) & \rightleftharpoons 2 \mathrm{GaH}(g) .
\end{aligned}
$$

The small film thickness of samples grown at high reactor pressure is probably caused by the increase in hydrogen partial pressure in the reactor due to the higher overall pressure. This hydrogen partial pressure changes the ratio between GaN growth and the etching of $\mathrm{GaN}$ by hydrogen more toward the latter ${ }^{21}$ and, thus, the resulting GaN layer remains very thin.

\section{B. V/III-ratio}

Alteration of the V/III ratio is reported to give good control on the early stages of $\mathrm{GaN}$ growth ${ }^{24}$ and has been shown to greatly influence the characteristics of the grown epilayer. ${ }^{25}$ Because of the variation in lateral growth speed with $\mathrm{V} / \mathrm{III}$ ratio, it is also commonly employed as a steering parameter in lateral epitaxial overgrowth. ${ }^{26}$ In this study, its influence is tested by altering the amount of $\mathrm{NH}_{3}$. Sample D is prepared with less $\mathrm{NH}_{3}$ (thus lower V/III ratio), while, in sample $\mathrm{E}$, the $\mathrm{NH}_{3}$ flow and V/III ratio are increased. The overall amount of gas in the reactor is kept constant by compensating the change in ammonia with the carrier gas flow. Sample A is the reference sample.

Figure 2 shows that the preferred (0001) orientation of the GaN crystals with respect to the substrate is lost when more ammonia is added (from left to right). As a result, the crystals show a more or less random orientation, devoid of any epitaxial relationship, due to the excess ammonia.

Sample D (Fig. 2(a)), however, prepared with a decreased ammonia flow and thus lower V/III ratio, looks quite similar to the reference sample. Profilometric measurements of both samples show the growth rate to be very similar (0.80 and $0.85 \mu \mathrm{m}$ for samples A and D, respectively), and the (0001) oriented top faces of the GaN crystals are smooth, as observed in SEM. On the other hand, the GaN islands in sample A have much steeper edges than the almost trapezoid form of the crystals in sample D. This is directly visible in the SEM images (Fig. 2(a) and 2(b)), where the sides of the crystals (white) are in clear contrast with the top face (gray). However, as the nucleation density differs much between the samples, no real dependence on the lateral growth rate can be obtained.

Furthermore, counterintuitively, the grown layer in sample E has a smaller thickness, although more growth material (ammonia) is present in the reactor as compared to the reference sample. The thickness remains constant with less ammonia. An extra sample (F) has been prepared with twice as much TMG, and the result is compared with the reference sample in Fig. 3. It depicts a similar morphology as sample $\mathrm{D}$, but the layer is doubled in thickness due to the increased TMG flow, 1.55 and $0.74 \mu \mathrm{m}$, respectively. This shows that the growth rate is mainly dependent on the gallium concentration in the reactor. In this gallium-limited growth regime, the growth rate decreases with increasing ammonia flow, although the TMG flow is not changed. A possible cause for this effect is the raised viscosity due to the high ammonia content in the gas phase. This leads to reduced mass-transport in the diffusion layer, present just above the sample, and to a lower growth rate. ${ }^{21,27}$ It suggests the GaN growth under the reference conditions is mass-transport limited. Furthermore, a higher amount of ammonia can also result in a site blocking effect: ammonia will compete with gallium and

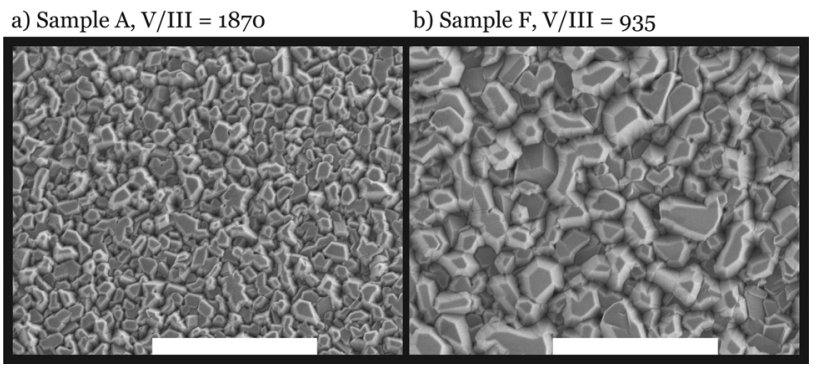

FIG. 3. SEM images from the reference sample A (a) and sample F prepared with a double amount of TMG present in the reactor (b). The V/III ratio decreases from $\mathrm{V} / \mathrm{III}=1870$ for sample $\mathrm{A}$ to $\mathrm{V} / \mathrm{III}=935$ for sample $\mathrm{F}$ with TMG flows of 52.5 and $105 \mathrm{mmol} / \mathrm{min}$, respectively. The scale bars represent $5 \mu \mathrm{m}$. 
prevent it from attaching to sites where it is adsorbed. The areal density of sites blocked by ammonia adsorption will increase with increasing ammonia partial pressure, thus decreasing the overall growth rate. ${ }^{28}$

Although the morphology of the crystals is not altered significantly by the decrease in ammonia flow or increase in TMG flow, it is clearly visible from both Figs. 2 and 3 that a smaller amount of GaN crystals is obtained when growing at lower $\mathrm{V} / \mathrm{III}$ ratio. The crystals are also much larger than in the reference sample, and there is almost no height difference between the individual $\mathrm{GaN}$ crystals in these samples. Because no renucleation is observed, the lower amount of crystals can only be caused by a decrease in the island density produced during annealing of the nucleation layer with the decreased V/III ratio. For all samples (A, D, and F), the $\mathrm{GaN}$ layer fully covers the diamond substrate and no space is left between the crystals. This suggests that the deposited islands expand as far as possible until another island is reached, and the lateral growth is thus sufficient to form an epitaxial layer. Apparently, the islands cannot coalesce due to some barrier, like the extra energy necessary to produce dislocations at grain boundaries between adjacent crystallites. ${ }^{29-31}$

\section{Growth temperature}

The results obtained by the series in pressure and V/III ratio indicate that the growth of $\mathrm{GaN}$ on diamond is determined by the diffusion of gallium gas phase precursor material through the boundary layer onto the surface. If so, the growth rate should be independent on growth temperature, ${ }^{21}$ and, thus, this influence is tested next.

Figure 4 displays the SEM results for the specimens grown in this series with $1140^{\circ} \mathrm{C}$ (sample G), $1170^{\circ} \mathrm{C}$ (sample A), $1185^{\circ} \mathrm{C}$ (sample $\mathrm{H}$ ), and $1215^{\circ} \mathrm{C}$ (sample I) growth

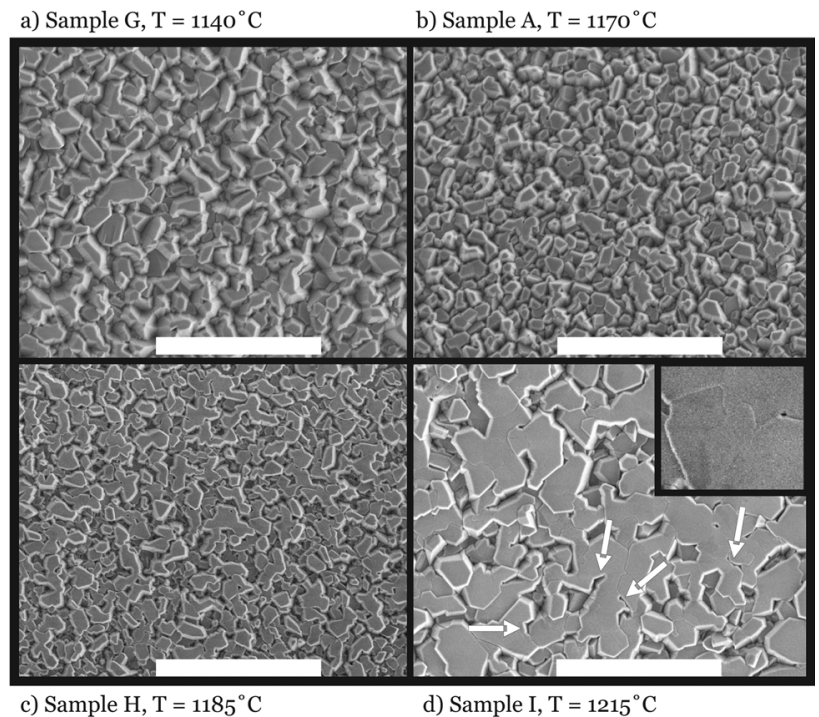

FIG. 4. SEM images of the series in growth temperature: a) sample G, grown at $1140^{\circ} \mathrm{C}, \mathrm{b}$ ) reference sample A prepared at $1170^{\circ} \mathrm{C}, \mathrm{c}$ ) sample $\mathrm{H}$ deposited at $1185^{\circ} \mathrm{C}$, and d) sample I, grown at a temperature of $1215^{\circ} \mathrm{C}$. The scale bars represent $5 \mu \mathrm{m}$. The inset shows an example of the observed low angle grain boundaries. temperature, respectively. All samples have constant GaN layer thickness of about $0.83 \mu \mathrm{m}$, thus, any differences observed among the layers are directly related to the difference in lateral growth rate by the change in temperature. The constant thickness again shows $\mathrm{GaN}$ growth on diamond is mass-transport limited just like the growth of $\mathrm{GaN}$ on sapphire and other III-V compounds. ${ }^{32}$

First, a sample $(\mathrm{G})$ is prepared at $1140{ }^{\circ} \mathrm{C}$, depicted in Fig. 4(a). It shows a GaN layer with less crystals in comparison to the reference sample A $\left(1170^{\circ} \mathrm{C}\right.$, Fig. $\left.4(\mathrm{~b})\right)$. Although the annealing time at the growth temperature was compensated for the different time in ramping to reach this final temperature, the lower nucleation density (resulting in less crystals) can originate from a small deviation in total annealing time.

By increasing the growth temperature to $1215^{\circ} \mathrm{C}$, which is the limit of the reactor applied, a prominent difference in the morphology of the sample (I, Fig. 4(d)) is observed as compared to the reference sample. Now, large areas of coalesced islands are formed, indicating a high lateral growth rate during crystal growth. This is consistent with the behavior previously reported by de Theije et al., ${ }^{22}$ who demonstrated the large influence of growth temperature on the formation of a coalesced epitaxial layer. Here, the SEM image shows that the GaN islands have different altitudes, and some have overgrown others in the lateral direction.

From the intermediate sample (H), depicted in Fig. 4(c) and grown at $1185^{\circ} \mathrm{C}$, it can be concluded that the transition to the high lateral growth is gradual. Sample $\mathrm{H}$ shows the nucleation density is constant with respect to the temperature. ${ }^{22}$ The large crystallite size in the high temperature sample $I$ is, thus, a consequence of advanced coalescence and overgrowth.

Although the largest crystallites are formed at the highest growth temperature, large-angle grain boundaries are present between the islands, as indicated by the white arrows in Fig. 4(d) (sample I). Apparently, with increased temperature, the energy barrier to include material in the grain boundary can be overcome (samples $\mathrm{H}$ and I). This leads to the formation of dislocations at the interface between two neighboring islands during the subsequent merging of these islands. This is different to the samples grown at lower temperature, where individual 3D islands are formed (samples A, B, D, F, and G). In addition to the large-angle grain boundaries, also low-angle grain boundaries can be observed in the SEM image of sample I (inset of Fig. 4(d)), as the boundary between two coalesced islands is still visible too.

Only in sample I, cracks in the GaN layer are observed (Fig. 6). These cracks originate from stresses built up during cooling as a result of the difference in thermal expansion coefficient between the (001) diamond substrate and the GaN with $\beta=1 \times 10^{-6} \mathrm{~K}^{-1}$ and $\beta=6.2 \times 10^{-6} \mathrm{~K}^{-1}$, respectively. ${ }^{33-35}$ The presence of the cracks in the layer also results from the increased coalescence of the GaN islands because cracks can only occur if the stress is built up over large areas. With no coalescence, the stresses are local, and the $\mathrm{GaN}$ islands can cope with them. In addition, cracks also imply a good adhesion of the grown layer to the substrate; otherwise, delamination would occur. 


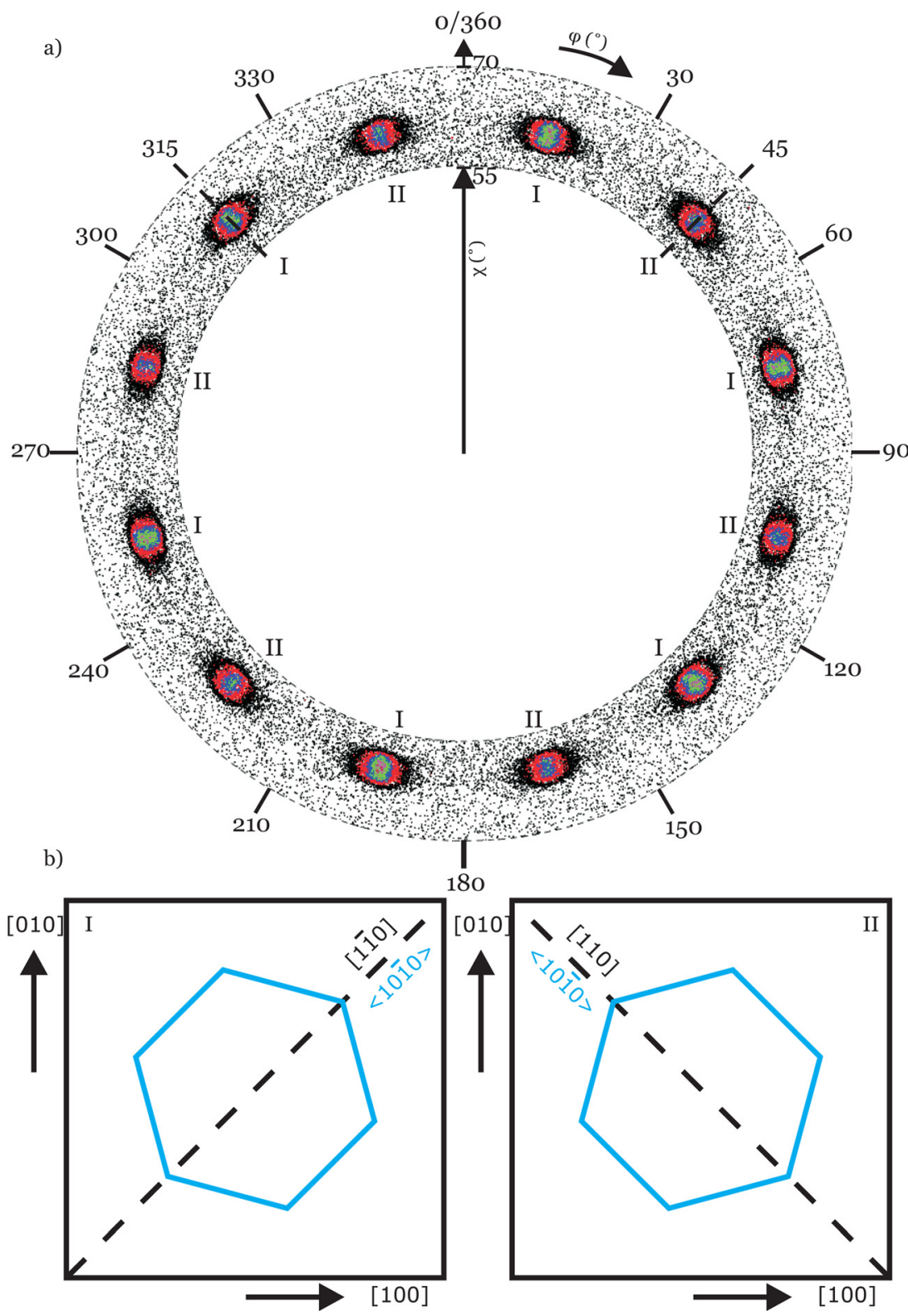

FIG. 5. (Color online) Pole figure obtained from the (1011) Bragg reflection of the GaN layer (a), and the preferred orientations with respect to the (001) diamond substrate (b).

\section{Texture analysis}

To further understand the formation process and epitaxial relationship, the in-plane orientation of the GaN layer with respect to the substrate was investigated by using XRD pole figure analysis. If the orientation of the $\mathrm{GaN}$ islands is randomly distributed, no specific $\mathrm{x}$ ray peaks can be identified and only a circle of increased intensity will be observed when measuring the reflection from a plane, not being (0001), over $360^{\circ}$. However, in the case of GaN, with its six-fold symmetry, a single preferred in-plane orientation will lead to six peaks, each separated by $60^{\circ}$. For this purpose, an extra sample was grown under equal conditions as sample I (Table 1), but with a longer growth time of 60 mins to ensure sufficient thickness for XRD pole figure analysis. SEM and profilometry showed the obtained morphology was similar, as presented in Fig. 4(d), but now with a layer thickness of $2.92 \mu \mathrm{m}$.
The XRD pole figure, depicted in Fig. 5(a), was obtained using the Schulz reflection method ${ }^{36}$ for the $(10 \overline{1} 1)$ reflection of the GaN layer, thus, with optimized parameters $\omega=18.38^{\circ}, 2 \Theta=36.76^{\circ}$ and $\chi=55-70^{\circ}$, and $\phi=0-$ $360^{\circ}$. In the displayed plot, twelve peaks of high intensity can be distinguished with $30^{\circ}$ relative difference. Considering the six-fold symmetry of $\mathrm{GaN}$, resulting in six reflection peaks separated by $60^{\circ}$, this means that there are two preferred orientations of $\mathrm{GaN}$ on (001) diamond. These domains are rotated $30^{\circ}$ with respect to each other and are denoted I and II in Fig. 5(a) for convenience of discussion. The measured XRD pole figure data are recapitulated in Table II. In Fig. 6, which is a small section of sample I, the different orientations, reflected by the $\{1 \overline{1} 01\}$ side faces, can be observed clearly. Possibly, this $30^{\circ}$ difference in orientation of the two domains is the reason why adjacent islands do not coalesce in the samples discussed in Secs. III A and III B and explains the large-angle grain boundaries in the SEM 
TABLE II. Overview of the reflection peaks observed in the XRD pole figure depicted in Fig. 5(a).

\begin{tabular}{lcrc}
\hline \hline Number & Domain & Position $\phi\left(^{\circ}\right)$ & Position $\chi\left(^{\circ}\right)$ \\
\hline 1 & I & $14.7 \pm 0.6$ & $61.3 \pm 0.7$ \\
2 & II & $45.1 \pm 0.7$ & $61.2 \pm 0.6$ \\
3 & I & $74.6 \pm 0.6$ & $60.9 \pm 0.6$ \\
4 & II & $105.0 \pm 0.6$ & $60.9 \pm 0.6$ \\
5 & I & $134.9 \pm 0.5$ & $60.9 \pm 0.6$ \\
6 & II & $165.2 \pm 0.5$ & $60.9 \pm 0.5$ \\
7 & I & $195.0 \pm 0.8$ & $60.9 \pm 0.7$ \\
8 & II & $225.3 \pm 0.7$ & $61.0 \pm 0.6$ \\
9 & I & $255.1 \pm 0.6$ & $61.3 \pm 0.7$ \\
10 & II & $285.1 \pm 0.5$ & $61.5 \pm 0.5$ \\
11 & I & $315.2 \pm 0.8$ & $61.8 \pm 0.5$ \\
12 & II & $345.1 \pm 0.6$ & $61.5 \pm 0.6$ \\
\hline \hline
\end{tabular}

images (Subsection III C). The low-angle grain boundaries observed in SEM originate from the spread within one orientation, typically $1-1.5^{\circ}$ in the $\phi$ direction.

The full determination of the in-plane texture requires the plot of two sets of pole figures or the substrate orientation to be known with respect to the rotation axis. Here, the latter is used because the diamond substrate was mounted with the [100] diamond direction parallel to the $\chi$-rotation axis and the [010] direction along the $\omega$-rotation axis with an estimated mounting error of $1^{\circ}$. As the (1011) reflection peaks 2 and 11 are observed at positions $\phi=45.1^{\circ}$ and $\phi=315.2^{\circ}$, respectively, it follows that the two $\mathrm{GaN}$ growth domains are aligned with their $\langle 10 \overline{1} 1\rangle$ along the [110] and [1 10$]$ diamond directions, as depicted in Fig. 5(b). The two growth domains thus are oriented $90^{\circ}$ with respect to each other, which corresponds to the four-fold symmetry of the (001) diamond surface. These results are in good agreement with comparable heteroepitaxial systems, like $\mathrm{GaN}$ on (001) $\mathrm{Si}^{37} \mathrm{AlN}$ on (001) $\mathrm{Si}^{38}$ and AlN on (001) diamond. ${ }^{39,40}$ In all cases, two growth domains rotated $90^{\circ}$ with respect to each other were found, with the $\langle 10 \overline{1} 1\rangle$ crystal domains aligned along the [110] and [1 $\overline{1} 0]$ directions of the underlying substrate. Therefore, it can be concluded that the growth of $\mathrm{GaN}$ on (001) diamond is similar to the forementioned systems, and the predominant epitaxial orientation of growth domain $\mathrm{I}$ is (0001) $\langle 10 \overline{1} 0\rangle \mathrm{GaN} \|$ (001) [1 10$]$ diamond and (0001) $\langle 10 \overline{1} 0\rangle \mathrm{GaN} \|$ (001) [110] diamond for domain II.

The pole figure provides additional useful information on the $\mathrm{GaN}$ layer. From the peak position in the $\chi$-direction, for instance, an estimate of the stress in the GaN layer can be determined. On average, the twelve peaks are positioned at an angle of $\chi=61.2^{\circ}$ with a spread of $0.6^{\circ}$ along the rotation of $\phi$. This spread is an indication of the misalignment of the diamond substrate, but this effect is canceled out by the $\phi$ rotation in the average. From the lattice parameters of stress free bulk GaN $(a=3.189 \AA \text { and } c=5.186 \AA)^{35}$, the theoretical angle of the (10 $\overline{1} 1)$ plane with respect to $(0001)$ is calculated to be $61.96^{\circ}$. Because the theoretical angle is larger than the experimental value, it can be deduced that the ratio $c / a$ is lower in the grown layer, which implies an amount of tensile stress parallel to the surface. This stress can partly be explained by the difference of the thermal expansion coefficients of $\mathrm{GaN}\left(\beta_{\mathrm{GaN}}=6.2 \times 10^{-6} \mathrm{~K}^{-1}\right.$ and $\left.\beta_{\text {diamond }}=1 \times 10^{-6} \mathrm{~K}^{-1}\right)$. During cooling down, this leads to a strain increase of

$$
\Delta \varepsilon=\Delta T \times\left(\beta_{\text {diamond }}-\beta_{\text {GaN }}\right),
$$

with $\Delta T$ the difference in temperature $\left(1190^{\circ} \mathrm{C}\right)$. For the present case, this gives a tensile strain of $\Delta \varepsilon=-6.2 \times 10^{-3}$, which corresponds with an increase of $a$-axis length of $\Delta a=0.020 \AA$. Assuming a constant $c$-axis length, the angle between the (1011) and (0001) planes should become $61.81^{\circ}$, which only partially explains the observed value of $\chi=61.2^{\circ}$.

It should be mentioned here that the observed epitaxial growth of $\mathrm{GaN}$ on diamond is quite surprising in view of the fact that the surface symmetry of GaN does not correspond with the four-fold symmetry of the (001) diamond plane. In addition, the lattice mismatch

$$
f=100 \times \frac{\left|a_{\text {GaN }}-a \sqrt{2}_{\text {diamond }}\right|}{\left(a \sqrt{2}_{\text {diamond }}\right)}=36.8 \%
$$

is extremely large. Here, $a_{\text {GaN }}$ is $3.189 \AA$, and $a \sqrt{2}_{\text {diamond }}$ (with $a_{\text {diamond }}=3.567 \AA$ ) is the unit translation of diamond along $\langle 110\rangle$.

\section{INFLUENCE ON STRUCTURAL PROPERTIES}

To further investigate the structural properties of the GaN layers, for each sample, a $\mu$-Raman spectrum was acquired. All spectra have an intense peak at $1332.3 \mathrm{~cm}^{-1}$ $\left(\mathrm{FWHM}=6.0 \mathrm{~cm}^{-1}\right)$ attributed to diamond and an area in which the GaN modes are observed. As the diamond peak is not shifted with respect to bare diamond and no carbon $\mathrm{sp}^{2}$ peaks ${ }^{41}$ are observed, it can be concluded that the diamond substrate keeps its quality throughout the GaN growth process, and no graphitic interlayers are formed, as is consistent with earlier work. ${ }^{11}$ Based on the Raman signals in the GaN area $\left(200 \mathrm{~cm}^{-1}-800 \mathrm{~cm}^{-1}\right)$, the spectra obtained can be

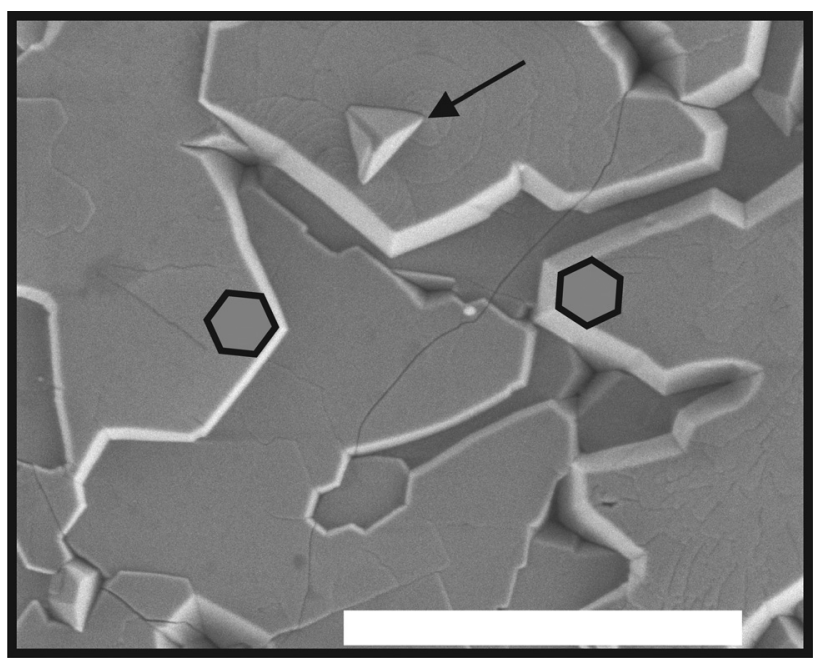

FIG. 6. Close up of the sample I, prepared at $1215^{\circ} \mathrm{C}$, depicting the two growth domains in the GaN layer. Two cracks can be recognized as well. The scale bar represents $5 \mu \mathrm{m}$. 


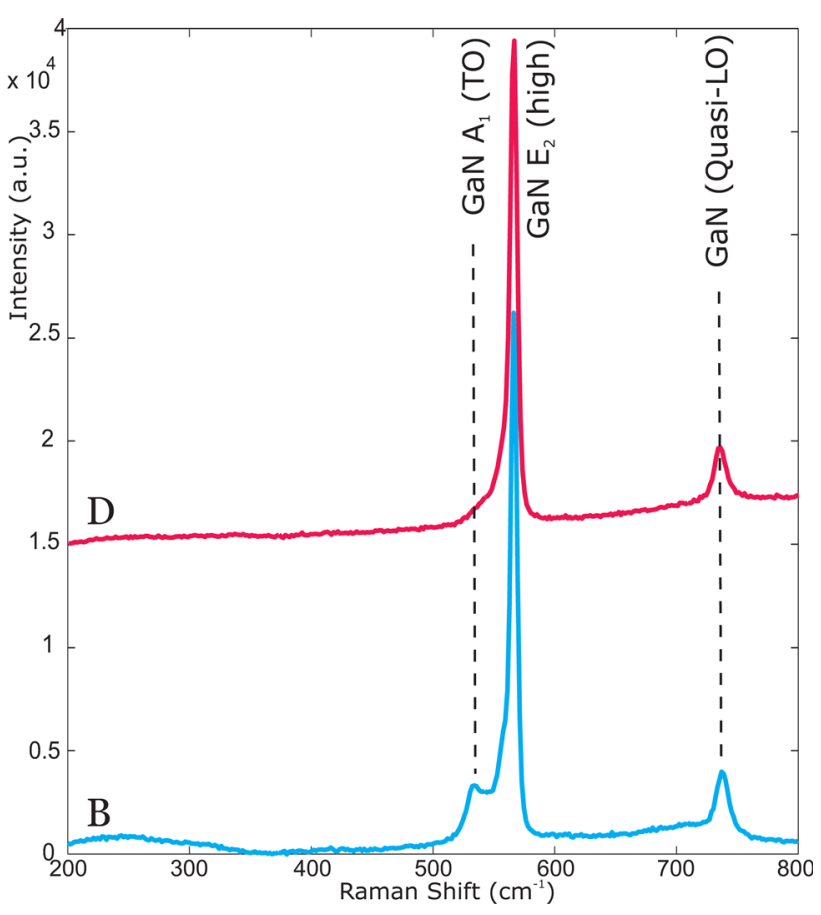

FIG. 7. (Color online) Raman spectra from typical ordered (D) and disordered (B) samples.

classified in two categories for each of which a typical measurement is displayed in Fig. 7.

The spectrum of sample $\mathrm{D}$ is typical for the GaN layers in experiments A, C, D, F, G, H, and I. It shows the two Raman active optical phonon modes that, in theory, can be measured in this wavenumber range for hexagonal $\mathrm{GaN}$ in backscattering geometry if the $\mathrm{GaN}$ is $c$-axis oriented, i.e., $\mathrm{A}_{1}$ (LO) and $\mathrm{E}_{2}$ (high). ${ }^{42}$ The $\mathrm{E}_{2}$ (low) can, in principle, also be observed in hexagonal $\mathrm{GaN}$, but it has a phonon frequency of $144 \mathrm{~cm}^{-1}$ and, therefore, is not visible in the displayed spectra. The $\mathrm{A}_{1}$ (LO) phonon mode is here denoted as $\mathrm{GaN}$ (quasi-LO) because of its potential mixing with $\mathrm{E}_{1}$ (LO) to produce a carrier concentration dependent coupled longitudinal optical mode. ${ }^{43,44}$

For all the samples in this category, the above-mentioned $\mathrm{E}_{2}$ (high) and the quasi-LO are clearly visible, respectively at $565.5 \mathrm{~cm}^{-1}$ and $734.4 \mathrm{~cm}^{-1}$, indicating that some stress is present in the samples. The peak wavenumber for the $E_{2}$ (high) is slightly lower than the value obtained for bulk GaN, thus demonstrating a small tensile stress in the layer, which is estimated at $0.4 \mathrm{GPa}$ from the relation ${ }^{45}$

$$
\Delta \omega=6.2 \times \sigma,
$$

where $\Delta \omega$ is the determined Raman shift and $\sigma$ is the stress in GPa.

For the remaining samples (B and $\mathrm{E}$ ), the spectrum is slightly different and, as an example, the acquired Raman spectrum for sample B is displayed. For these layers, an extra peak is detected at $535 \mathrm{~cm}^{-1}$, which is attributed to $\mathrm{A}_{1}$ (TO). Often the $A_{1}(T O)$ is observed when the incident light is not exactly normal to the (0001) surface of the GaN crystals, for instance, if the layer is tilted, if it has a higher mosaicity, ${ }^{46}$

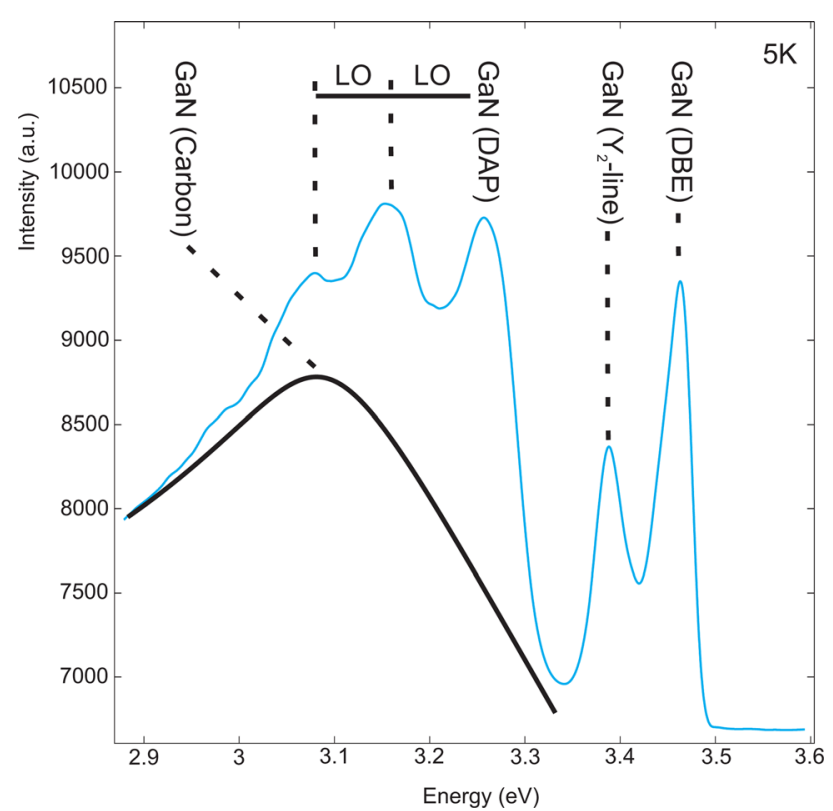

FIG. 8. (Color online) Typical PL spectrum for the growth of GaN on nominal (001) diamond, taken from sample H. The black line displays the assumed contribution of luminescence by carbon doping to the spectrum.

or when the layer is polycrystalline and consists of differently orientated crystals. Here, the latter is the case, as follows from the SEM images (Figs. 1(a) and 2(c)).

Furthermore, the spectrum of sample B displays a small distortion and a slightly shifted position of the quasi-LO peak at $737.9 \mathrm{~cm}^{-1}$. The cause for this difference could not be determined unambiguously, but it most likely originates from a larger carrier concentration (about $\alpha=1.5 \times 10^{17}$ $\mathrm{cm}^{-3}$ ), resulting in LO phonon-plasmon coupling of which the $\mathrm{L}^{+}$branch is at $738 \mathrm{~cm}^{-1}$ and the $\mathrm{L}^{-}$branch is just visible at $244 \mathrm{~cm}^{-1}$. 44

\section{INFLUENCE ON OPTICAL PROPERTIES}

Next, the optical properties are investigated using photoluminescence (PL) spectroscopy. All spectra show the same features, only distinguished by changes in the relative intensity. No features from the diamond substrate are observed, and a typical PL spectrum is depicted in Fig. 8.

On the right side of the plot, a set of two distinct peaks are observed. Here, the peak at $3.466 \mathrm{eV}$ has higher intensity than the emission found at $3.388 \mathrm{eV}$, but, from other spectra, it was deduced that the intensities are not related to each other. The peak distinguished at $3.466 \mathrm{eV}$ with a FWHM of $36 \mathrm{meV}$ is ascribed to the donor bound exciton (DBE) emission of wurtzite $\mathrm{GaN},{ }^{47}$ but the position here is slightly lower than normally found, indicating tensile stress in the GaN. ${ }^{48}$ This is consistent with the findings discussed in Secs. III D and IV. The second peak cannot be related to acceptor bound recombination (ABE) because the energy distance $(78 \mathrm{meV}$ ) from the DBE peak is too large. Instead, it is attributed to the less commonly observed $\mathrm{Y}_{2}$ line, ${ }^{49}$ normally detected at 3.40 $\mathrm{eV}$, but, again, the emission can be shifted toward lower energy due to tensile stress. The $\mathrm{Y}_{2}$ line is reported to be 
influenced by acceptor doping ${ }^{49}$ (like carbon) and is strongly related to stacking faults parallel to the substrate/film interface, ${ }^{50,51}$ which originate from the overgrowth in the lateral direction of GaN islands with different altitudes, as described above in Sec. III C.

The broad peak in the lower energy section of Fig. 8 actually consists of two systems. The main band is most likely related to carbon doping in the GaN layer, which is known to produce a broad emission focused around 3.07 $\mathrm{eV} .^{49}$ Additionally, a system with three peaks is observed in most layers. It was found that this system is much more resolved when the DBE peak of GaN has a relatively high intensity, and it is attributed to donor-acceptor pair (DAP) transitions. Indeed, the higher intensity of the DBE line suggests a higher concentration of donors, which also participate in the donor-acceptor pair recombination. The DAP transitions are usually enhanced in films which are not simply $n-$ or $p$-doped, but have rather compensated character, showing the presence of both donors and acceptors. In addition, there is a very effective coupling of the DAP and the DBE to longitudinal optical (LO) phonons of the DAP with energy of about $92 \mathrm{meV}$. Due to this coupling of photons with the LO-phonons, not only the direct transitions are seen in Fig. 8, but also their LO-phonon replicas, i.e., transitions with simultaneous emission (or absorption) of a photon and one or more phonons. ${ }^{52}$ Here, the energy separation between the first two peaks is close to $100 \mathrm{meV}$ rather than $92 \mathrm{meV}$ for the LO phonon energy. This could be due to the superposition of defect lines around $3.15 \mathrm{eV}$ onto the standard DAP related luminescence.

\section{OFF-AXIS SUBSTRATES}

As demonstrated in Sec. III D, the growth of GaN on nominal (001) diamond produces two growth domains with a $90^{\circ}$ angular difference in orientation caused by the four-fold symmetry of the substrate. The same phenomenon has been observed in the epitaxial growth of $\mathrm{GaN}$ on (001) Si. The reason for this is the fourfold symmetry of the substrate and the possibility for GaN, with its sixfold symmetry, to grow with two preferred rotational alignments on this surface if AlN seed layers are applied. Considering the large resemblance between the silicon and diamond lattice structures, it can be expected that, here, surface reconstruction also plays an important role. For (001) $\mathrm{Si}$ in conditions $>1000^{\circ} \mathrm{C}$, it was found that the surface reconstructs in a $(2 \times 1)$ and $(1 \times 2)$ reconstruction, reducing the fourfold symmetry of the crystal surface to a twofold symmetry. ${ }^{53}$ Indeed, for diamond, both modeling ${ }^{54,55}$ and experimental observation by scanning tunneling microscopy ${ }^{56,57}$ have shown the hydrogen terminated surface and $(2 \times 1)$ and $(1 \times 2)$ dimer formation too. ${ }^{58}$ The dimers formed by reconstruction of the diamond or $\mathrm{Si}$ surface are aligned along the [110] or the [110] directions, and the reconstructed domains are separated by one monolayer in height. Because the diamond substrates are not atomically flat, both reconstruction orientations can occur in close approximation of each other, leading to a random distribution of the two GaN growth domains. However, if one of these surfaces, either with the $(1 \times 2)$ or the perpen-
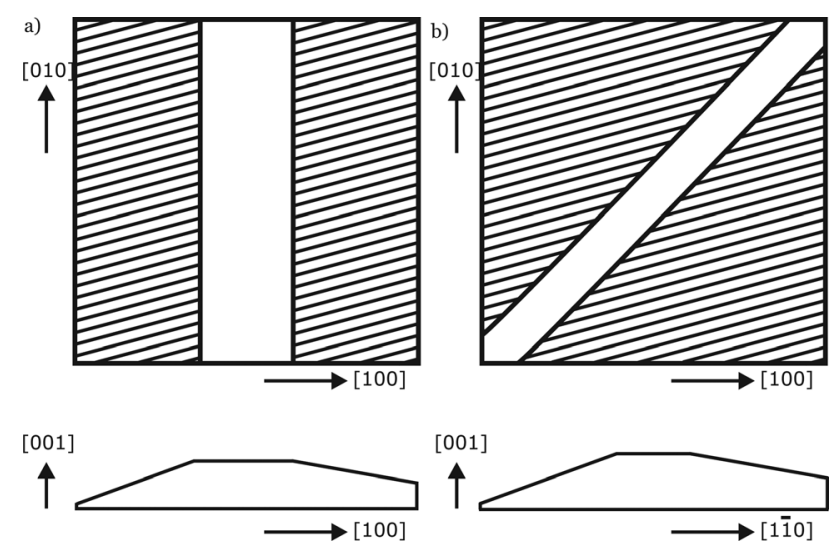

FIG. 9. Schematic representation of the vicinal substrates used in this study. Top and side views of the polished diamond with the off-axis orientation toward [100] direction (a) and toward [1 $1 \overline{1} 0]$ direction (b).

dicular $(2 \times 1)$ reconstruction, is suppressed, the other can be used for single crystalline $\mathrm{GaN}$ growth. This suppression can be achieved by forming biatomic steps using off oriented substrates $^{59}$ or by applying tensile or compressive strain on the substrate. ${ }^{60}$ While the latter method is difficult to apply, the first can be tested much easier by polishing an angle on the (001) diamond substrate.

\section{A. Substrates}

For this purpose, nominal (001) diamonds, supplied by Element Six with a maximum deviation of $3^{\circ}$ from the (001) plane, have been polished by a commercial company (Wiediam VOF, Wanroy, The Netherlands) to add off-axis facets to the substrate. Each diamond has been polished to have two off-axis facets and one nominal facet for comparing the growth results with the forementioned series. Even though it is very difficult to establish a predefined angle, substrates with various mis-orientation angles toward different crystallographic planes are prepared, as depicted schematically in Fig. 9. After polishing, the diamonds are cleaned in boiling $\mathrm{H}_{2} \mathrm{SO}_{4}$, subsequently followed by heated aqua regia, rinsing in $\mathrm{H}_{2} \mathrm{O}(4 \mathrm{x})$ and isopropanol (3x). Finally, just before the MOCVD growth, the substrates are cleaned following the procedure described in Sec. II.

Because of the uncertainty in the substrate orientation for both the "nominal" surfaces and the added off-axis facets, first, the misorientation between the surface and the (001) lattice plane is determined for each facet. For this, the diamond sample is mounted on a goniometer head inside the XRD setup and aligned with a laser in such a way that the position of the reflected beam does not vary upon rotation of the sample (Fig. 10(a)). Then, the optimized $\omega, 2 \Theta$, and $\chi$ for the Bragg-Brentano reflection of the (004) diamond plane are determined, as schematically shown in Fig. 10(b). The extra angular difference between $\omega$ and half of the $2 \Theta$ value is then used in combination with the measured $\chi$ value to calculate the vicinal angle of the facet. The angles of a representative selection of the samples are summarized in Table III. The error in the obtained angles is estimated at $0.1^{\circ}$. As it is more difficult to polish a vicinal 
a)
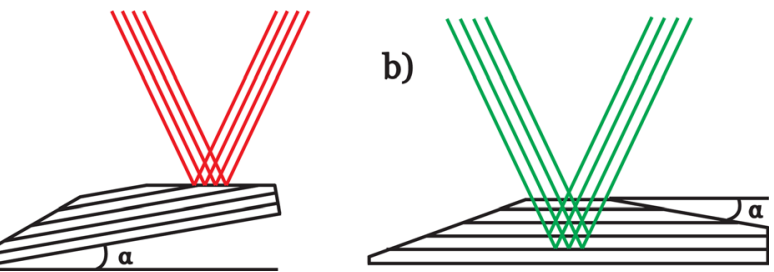

FIG. 10. (Color online) Schematic representation of the two-step determination of the angle $\alpha$ of misoriented facets in this study. Alignment of the sample surface using the laser beam (a) and subsequent measurement of the $\mathrm{x}$ ray reflection from (004) diamond lattice planes (b).

facet toward the [100] direction, the off-axis angle of these specimens is, on average, lower than of those polished toward the [110] direction.

\section{B. Vicinal direction toward [100]}

For this part of the studies, the same growth conditions were used as listed for sample I in Table 1. SEM images of the results are depicted in Fig. 11. The two images at the top of the figure (samples J and L) display the morphology of the "nominal" sections of the sample (the central section in Fig. 9(a)). It shows that the layers are slightly less coalesced as described for sample I. This can be due to a less optimal contact between the substrate and the susceptor in the MOCVD reactor during growth, for instance, caused by increased roughness of the backside of the substrate, which, in turn, leads to a lower temperature at the substrate surface and, thus, to a decrease in lateral growth as seen in Sec. III C.

The samples $\mathrm{M}$ and $\mathrm{O}$ (with vicinal angles 3.6 and $8.3^{\circ}$ ) are displayed to demonstrate the large simularity between layers grown on the substrates with higher off-axis angles. When comparing the SEM images, it can be concluded that increasing the misorientation $>3^{\circ}$, the average size of the top layer of $\mathrm{GaN}$ islands is increased, probably due to more step flow growth induced by the extra steps as a consequence of the off-axis surface. Again, it was observed that crystals with larger height overgrow the neighboring islands laterally. By inspection of the orientation of the inclined $\{1 \overline{1} 01\}$ side facets, both growth domains are identified in the GaN crystals for all experiments.

TABLE III. Overview of the samples used in these studies on vicinal (001) diamond substrates.

\begin{tabular}{lcc}
\hline \hline Sample & $\begin{array}{c}\text { Off-axis Angle } \\
\alpha\left(^{\circ}\right)\end{array}$ & $\begin{array}{c}\text { Vicinal Direction } \\
\text { Towards }\end{array}$ \\
\hline $\mathrm{J}$ & 2.0 & {$[100]$} \\
$\mathrm{K}$ & 2.2 & {$[100]$} \\
$\mathrm{L}$ & 2.7 & {$[100]$} \\
$\mathrm{M}$ & 3.6 & {$[100]$} \\
$\mathrm{N}$ & 6.5 & {$[100]$} \\
$\mathrm{O}$ & 8.3 & {$[100]$} \\
$\mathrm{P}$ & 2.6 & {$[110]$} \\
$\mathrm{Q}$ & 2.7 & {$[110]$} \\
$\mathrm{R}$ & 5.9 & {$[110]$} \\
$\mathrm{S}$ & 6.7 & {$[110]$} \\
$\mathrm{T}$ & 9.0 & {$[110]$} \\
$\mathrm{U}$ & 11.0 & {$[110]$} \\
\hline \hline
\end{tabular}

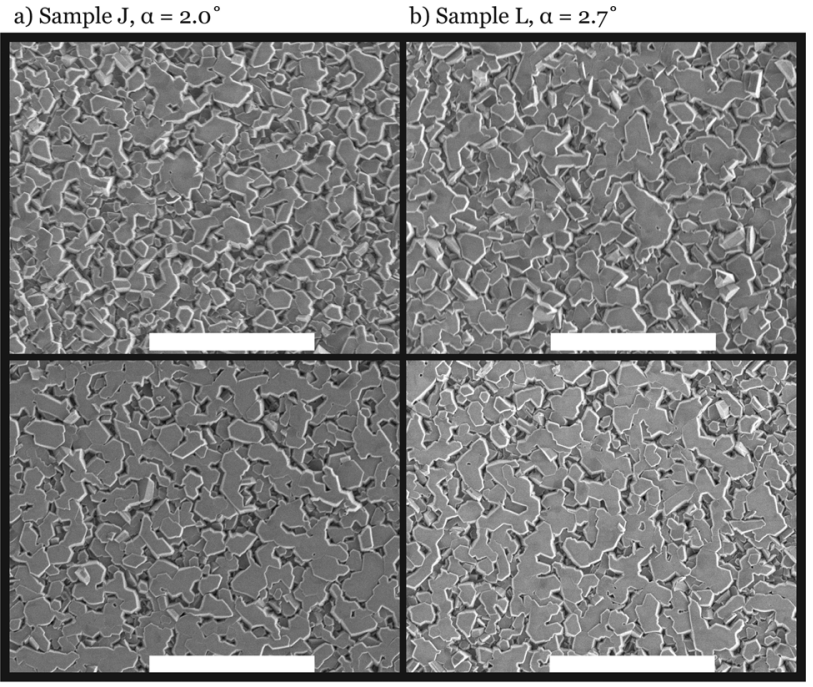

c) Sample M, $\alpha=3.6^{\circ}$

d) Sample O, $\alpha=8.3^{\circ}$

FIG. 11. SEM images of the series in vicinal angle toward the [100] direction: a) sample $\mathrm{J}$, grown on a facet with $2.0^{\circ}$ misorientation, b) sample $\mathrm{L}$ prepared on a $2.7^{\circ}$ misoriented substrate, c) sample $\mathrm{M}$, deposited at a vicinal angle of $3.6^{\circ}$, and d) sample $\mathrm{O}$, grown at an off-axis facet of $8.3^{\circ}$. The scale bars represent $5 \mu \mathrm{m}$.

\section{Vicinal direction toward [110]}

Finally, GaN layers on (001) diamond substrates with vicinal orientation toward [110] are prepared by applying the conditions used for the growth of sample I (Table I). Sample P (Fig. 12(a)) shows the layer produced on "nominal" diamond as a standard for comparison of the results. With increasing misorientation, the $\mathrm{GaN}$ islands become larger, as depicted for samples R and S, which is also observed in Sec. VI B. However, now the distribution between the two growth domains (I and II, Sec. III D) is changed in comparison to samples on nominal (001) diamond, where the relative population is about $50 \%$ for either growth domain. This was

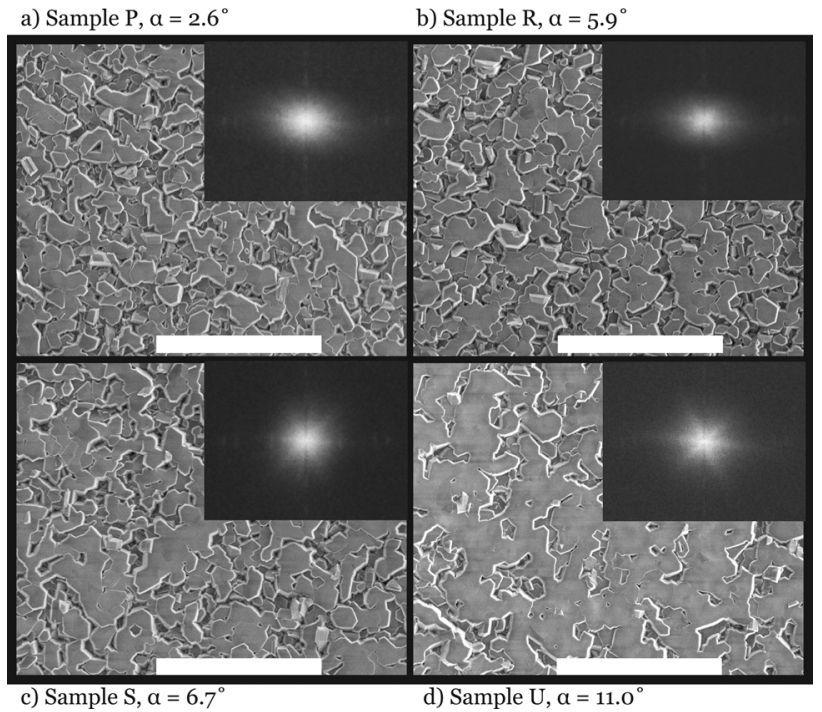

FIG. 12. SEM images of the GaN growth on misoriented diamond surface toward the [110] direction: a) $2.6^{\circ}$ for sample P, b) $5.9^{\circ}$ for sample R, c) sample $\mathrm{S}$, deposited on a $6.7^{\circ}$ misoriented substrate, and d) sample $\mathrm{U}$, grown at a vicinal angle of $11.0^{\circ}$. The insets show the calculated Fourier Transform of the corresponding SEM image. The scale bars represent $5 \mu \mathrm{m}$. 


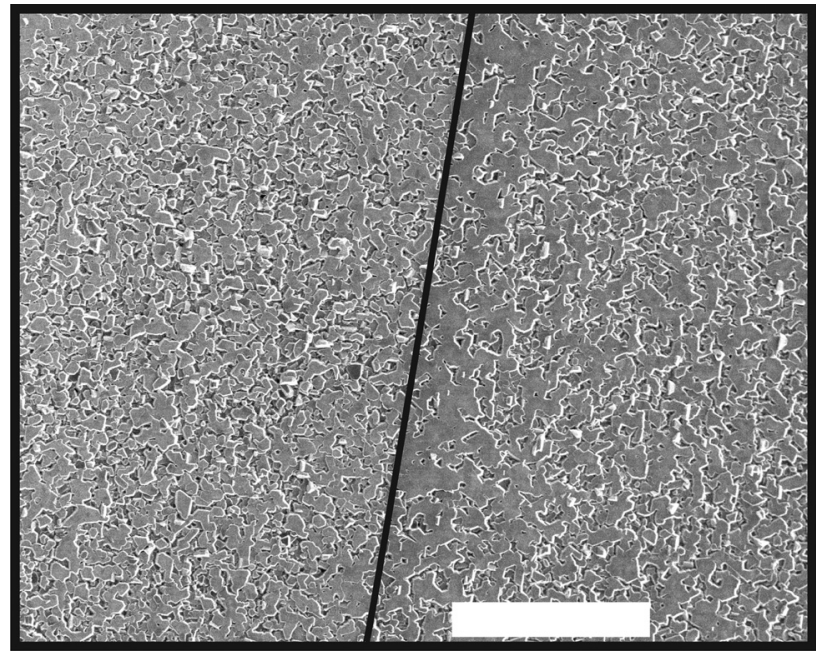

FIG. 13. SEM image of a GaN layer grown on a diamond surface misoriented toward the [110] direction. The black line, which runs parallel to the [110] direction, indicates the transition from a slightly to a highly misoriented substrate. Left of the black line, the misorientation is $2.6^{\circ}$, while, on the right side, the off-axis angle is $11.0^{\circ}$. The scale bar represents $20 \mu \mathrm{m}$.

deduced from the relative occurrences of the different orientations of the inclined $\{1 \overline{1} 01\}$ side faces of the crystallite layers. The layer of sample U (Fig. 12(d)), obtained with $11.0^{\circ}$ angle toward, [110] consists of large areas of single domain hexagonal GaN.

Figure 13 shows an SEM image of GaN deposited near the transition from a $2.6^{\circ}$ to an $11.0^{\circ}$ misorientated surface (samples $\mathrm{P}$ and $\mathrm{U}$ ). The black line indicates the $[1 \overline{1} 0]$ direction of the diamond, along which the steps orient. Here, it is clearly visible that, at the misorientation of $2.6^{\circ}$, two growth domains are present in the layer, while, for the $11.0^{\circ}$ offaxis surface, an abrupt transformation to only one growth domain is displayed, and the side faces of the GaN islands are aligned parallel to the $[1 \overline{1} 0]$ line. The film at this location of the sample is not as well coalesced as observed in Fig. 12, probably caused by temperature effects. Furthermore, the growth can be influenced by extra roughness in the diamond surface due to grooves along the [100] direction resulting from the polishing, ${ }^{61}$ as confirmed by optical microscopy. Some twinning in the GaN is observed in all samples in these studies, which may be attributed to these polishing effects. An example is indicated by the arrow in Fig. 6. Possibly, some debris from the polishing was also still present at the surface, prior to growth, causing these defects.

Corresponding to reported growth on vicinal (001) Si, the dominance of one growth domain on highly misoriented substrates is likely attributed to the increase of the number of double steps on the substrate surface. ${ }^{59}$ As mentioned above, the diamond surface is reconstructed by $(2 \times 1)$ and $(1 \times 2)$ dimers at high temperatures. When the miscut is relatively low, only single-height-atomic steps are expected to occur on the surface, and these are known to produce a $90^{\circ}$ rotation of the dimers on every next terrace due to the diamond lattice structure of the substrate. ${ }^{62}$ This leads to the growth of the two different growth domains of GaN. However, when the miscut angle is increased, the surface will contain more double-height-atomic steps and the dimer direction does no longer change on adjacent terraces. This implies that the $\mathrm{GaN}$ islands nucleated on neighboring terraces will be aligned in the same direction, and single domain (0001) GaN is obtained. As stable steps on reconstructed (001) diamond surfaces are aligned along the dimer [110] and [1히 directions, double height steps are not easily formed on diamonds with vicinal direction toward [100]. Therefore, for these substrates, both surface reconstruction domains persist and no single crystal GaN will be formed, regardless of the misorientation angle.

Alternatively, the growth of single domain GaN can also be enhanced by the orientation of the substrate steps. Similar to growth via pseudoepitaxy, ${ }^{63}$ the steps can act as nucleation sites for the GaN growth because addition of growth material is energetically more favorable there. However, the substrates with vicinal direction toward [110] have a distinguished advantage over the diamonds misoriented toward the [100] direction. Substrate steps on the latter are kinked, leading to nuclei oriented in two perpendicular directions, while the steps on substrates with vicinal direction toward [110] are straight. This leads to nuclei that are aligned in one direction, parallel to the steps, as is observed in Fig. 13. With increasing miscut angle, the terrace width becomes smaller and more steps are available, enhancing the probability to form aligned $\mathrm{GaN}$ nuclei. This results in subsequent single domain growth of $\mathrm{GaN}$ on diamond substrates with larger vicinal angles toward the [110] direction.

\section{Quality of the GaN layers on vicinal (001) diamond}

Due to the small sample size and the short growth time of 20 mins, it was not possible to confirm the single domain structure of $\mathrm{GaN}$ for the highly misoriented facets toward the [110] diamond direction by XRD pole figure analysis. Our evidence is based on the orientation of the $\{1 \overline{1} 01\}$ side facets of the GaN layers with respect to the $\langle 100\rangle$ diamond directions (Fig. 12), and it is supported by the calculated Fourier Transform (FT) of the SEM images (Fig. 12, insets). With increasing vicinal angle, the FT shows increased intensity for only six directions. This demonstrates that only one domain is preferred if a GaN layer is prepared on highly misoriented (001) diamond substrates.

Raman measurements for all GaN layers deposited on misoriented substrates produced spectra similar to the signal depicted in Fig. 7(B). The $\mathrm{A}_{1}$ (TO) relative peak intensity is increased with increasing vicinal angle and is independent of the orientation of the miscut. This is obviously caused by the fact that the incident light was not aligned exactly normal to the (0001) surface of the GaN film. Furthermore, for the layers on [110] misoriented diamond, the peak position of the $E_{2}$ (high) phonon mode moves toward the bulk GaN value of $568 \mathrm{~cm}^{-1}$ for higher vicinal angles. It appears that the stress developed during cooling of the sample from the growth temperature is released more in the largely coalesced GaN layers, as is also deduced from crack formation in the layer.

The optical properties for the wurtzite GaN layers grown on vicinal diamond have been studied intensively with PL 
spectroscopy and will be the subject of a forthcoming research article.

\section{CONCLUSIONS}

This research describes the influence of multiple growth parameters on the preparation of epitaxial GaN layers on (001) diamond by MOCVD. SEM and growth rate measurements of the obtained heterostructures show that the growth of $\mathrm{GaN}$ is determined by mass-transport of gallium precursor material toward the substrate. Lateral growth of the 3D GaN nuclei and subsequent coalescence is enhanced by increasing $\mathrm{V} / \mathrm{III}$ ratios and growth temperature. $\mathrm{X}$ ray pole figure analysis reveals two preferential growth orientations of the $\mathrm{GaN}$ layers on the (001) diamond surfaces, namely $(0001)\langle 10 \overline{1} 0\rangle$ GaN $\|$ (001)[110] diamond and (0001) $\langle 10 \overline{10}\rangle \mathrm{GaN} \|(001)$ [110] diamond, $90^{\circ}$ rotated with respect to each other. This is a consequence of the "incompatible" four-fold symmetry of the substrate and the hexagonal symmetry of the (0001) GaN contact face. Raman spectroscopy showed that the structural quality of the GaN layers on diamond is very similar to epitaxial GaN layers obtained on other materials, while the diamond substrate remains unaffected. PL spectroscopy showed an intense broad band caused by carbon doping as well as the presence of both donors and acceptors.

The growth on vicinal diamond faces, prepared with various miscut angles toward the [100] and [110] directions, supports the hypotheses that surface reconstruction by $(2 \times 1)$ and $(1 \times 2)$ dimer formation determines the preferred alignment. An epitaxial single crystal GaN layer is formed on vicinal (001) diamond faces, which are highly misoriented toward [110]. This is explained by the occurrence of di-atomic steps, resulting in one type of reconstruction domain with the $\mathrm{C}-\mathrm{C}$ dimers aligned in one direction all over the diamond substrate surface. Furthermore, the small distance between steps on the substrate at high miscut angle can also contribute to the enhanced preference for the observed single orientation, parallel to the diamond step-edge.

The main conclusion of this work is that the possibility of growing single crystalline GaN layers on (001) diamond substrates holds much promise for the development of high power GaN-based devices.

${ }^{1}$ R. Koda, T. Oki, T. Miyajima, H. Watanabe, M. Kuramoto, M. Ikeda, and H. Yokoyama, Appl. Phys. Lett. 97, 021101 (2010).

${ }^{2}$ Y. F. Wu, A. Saxler, M. Moore, R. P. Smith, S. Sheppard, P. M. Chavarkar, T. Wisleder, U. K. Mishra, and P. Parikh, IEEE Electron. Device Lett. 25, 117 (2004).

${ }^{3}$ E. Wörner, C. Wild, W. Müller-Sebert, R. Locher, and P. Koidl, Diamond Relat. Mater. 5, 688 (1996).

${ }^{4}$ M. Oba and T. Sugino, Diamond Relat. Mater. 10, 1343 (2001).

${ }^{5}$ P. W. May, H. Y. Tsai, W. N. Wang, and J. A. Smith, Diamond Relat. Mater. 15, 526 (2006).

${ }^{6}$ D. Francis, J. Wasserbauer, F. Faili, D. Babić, F. Ejeckam, W. Hong, P. Specht, and E. Weber, in Proc. CS MANTECH, Austin, Texas, 14-17 May 2007, p. 133.

${ }^{7}$ K. D. Chabak, J. K. Gillespie, V. Miller, A. Crespo, J. Roussos, M. Trejo, D. E. Walker, G. D. Via, G. H. Jessen, J. Wasserbauer, F. Faili, D. I. Babić, D. Francis, and F. Ejeckam, IEEE Electron. Device Lett. 31, 99 (2010).
${ }^{8}$ D. Francis, F. Faili, D. Babić, F. Ejeckam, A. Nurmikko, and H. Maris, Diamond Relat. Mater. 19, 229 (2010).

${ }^{9}$ J. W. Zimmer, Mater. Res. Soc. Symp. Proc. 956, J08.01 (2007).

${ }^{10}$ M. Rabarot, J. Widiez, S. Saada, J.-P. Mazellier, C. Lecouvey, J.-C. Roussin, J. Dechamp, P. Bergonzo, F. Andrieu, O. Faynot, S. Deleonibus, L. Clavelier, and J. P. Roger, Diamond Relat. Mater. 19, 796 (2010).

${ }^{11}$ G. W. G. van Dreumel, J. G. Buijnsters, T. Bohnen, J. J. ter Meulen, P. R. Hageman, W. J. P. van Enckevort, and E. Vlieg, Diamond Relat. Mater. 18, 1043 (2009).

${ }^{12}$ G. W. G. van Dreumel, T. Bohnen, J. G. Buijnsters, W. J. P. van Enckevort, J. J. ter Meulen, P. R. Hageman, and E. Vlieg, Diamond Relat. Mater. 19, 437 (2010).

${ }^{13}$ P. R. Hageman, J. J. Schermer, and P. K. Larsen, Thin Solid Films 443, 9 (2003).

${ }^{14}$ A. Dussaigne, M. Malinverni, D. Martin, A. Castiglia, and N. Grandjean, J. Cryst. Growth 311, 4539 (2009).

${ }^{15}$ A. Y. Polyakov, A. V. Markov, M. P. D. M. V. Mezhennyi, A. A. Donskov, S. S. Malakhov, A. V. Govorkov, Y. P. Kozlova, V. F. Pavlov, N. B. Smirnov, T. G. Yugova, A. I. Belogorokhov, I. A. Belogorokhov, A. K. Ratnikova, Y. Y. Fyodorov, O. Y. Kudryashov, I. A. Leontyev, V. I. Ratushnyi, and S. J. Pearton, J. Vac. Sci. Technol. B 28, 1011 (2010).

${ }^{16}$ M. Alomari, A. Dussaigne, D. Martin, N. Grandjean, C. Gaquiere, and E. Kohn, Electron. Lett. 46, 299 (2010).

${ }^{17}$ B. V. Spitsyn, W. L. Hsu, A. E. Gorodetsky, R. K. Zalavutdinov, A. P. Zakharov, L. L. Bouilov, V. P. Stoyan, V. F. Dvoryankin, and G. V. Chaplygin, Diamond Relat. Mater. 7, 356 (1998).

${ }^{18}$ M. Imura, K. Nakajima, M. Liao, Y. Koide, and H. Amano, J. Cryst. Growth 312, 1325 (2010).

${ }^{19}$ X. Zhang, S. J. Chua, Z. C. Feng, J. Chen, and J. Lin, Phys. Status Solidi A 176, 605 (1999).

${ }^{20}$ J.-H. Boo, S.-B. Lee, Y.-S. Kim, J. T. Park, K.-S. Yu, and Y. Kim, Phys. Status Solidi A 176, 711 (1999).

${ }^{21}$ G. B. Springfellow, Organometallic Vapor-Phase Epitaxy, Theory and Practice (Academic, Boston, 1989).

${ }^{22}$ F. K. de Theije, A. R. A. Zauner, P. R. Hageman, W. J. P. Enckevort, and P. K. Larsen, J. Cryst. Growth 197, 37 (1999).

${ }^{23}$ A. Koukito, M. Mayumi, and Y. Kumagai, J. Cryst. Growth 246, 230 (2002).

${ }^{24}$ T. Yang, K. Uchida, T. Mishima, J. Kasai, and J. Gotoh, Phys. Status Solidi A 180, 45 (2000).

${ }^{25}$ D. G. Zhao, D. S. Jiang, J. J. Zhu, Z. S. Liu, S. M. Zhang, H. Yang, and J. W. Liang, J. Cryst. Growth 303, 414 (2007).

${ }^{26}$ X. Zhang, P. D. Dapkus, and D. H. Rich, Appl. Phys. Lett. 77, 1496 (2000).

${ }^{27}$ S. Figge, T. Böttcher, S. Einfeldt, and D. Hommel, J. Cryst. Growth 221, $262(2000)$.

${ }^{28}$ O. Briot, S. Clur, and R. L. Aulombard, Appl. Phys. Lett. 71, 1990 (1997).

${ }^{29}$ T. Bohnen, A. E. F. de Jong, W. J. P. van Enckevort, J. L. Weyher, G. W. G. van Dreumel, H. Ashraf, P. R. Hageman, and E. Vlieg, J. Cryst. Growth 311, 4685 (2009).

${ }^{30}$ V. Lebedev, K. Tonisch, F. Niebelschütz, V. Cimalla, D. Cengher, I. Cimalla, C. Mauder, S. Hauguth, O. Ambacher, F. M. Morales, J. G. Lozano, and D. González, J. Appl. Phys. 101, 054906 (2007).

${ }^{31}$ J. L. Weyher, S. Lazar, L. Macht, Z. Liliental-Weber, R. J. Molnar, S. Müller, V. G. M. Sivel, G. Nowak, and I. Grzegory, J. Cryst. Growth 305, 384 (2007).

${ }^{32}$ D. W. Shaw, J. Cryst. Growth 31, 130 (1975).

${ }^{33}$ W. Qian, M. Skowronski, and G. S. Rohrer, Mater. Res. Soc. Symp. Proc. 423, 475 (1996).

${ }^{34}$ G. A. Slack and S. F. Bartram, J. Appl. Phys. 46, 89 (1975).

${ }^{35}$ M. Leszczynski, H. Teisseyre, T. Suski, I. Grzegory, M. Bockowski, J. Jun, S. Porowski, K. Pakula, J. M. Baranowski, C. T. Foxon, and T. S. Cheng, Appl. Phys. Lett. 69, 73 (1996).

${ }^{36}$ L. G. Schulz, J. Appl. Phys. 20, 1030 (1949).

${ }^{37}$ F. Schulze, A. Dadgar, J. Bläsing, T. Hempel, A. Diez, J. Christen, and A. Krost, J. Cryst. Growth 289, 485 (2006).

${ }^{38}$ V. Lebedev, J. Jinschek, U. Kaiser, B. Schröter, W. Richter, and J. Kräusslich, Appl. Phys. Lett. 76, 2029 (2000).

${ }^{39}$ G. Vogg, C. R. Miskys, J. A. Garrido, M. Hermann, M. Eickhoff, and M. Stutzmann, J. Appl. Phys. 96, 895 (2004).

${ }^{40}$ M. Imura, K. Nakajima, M. Liao, Y. Koide, and H. Amano, Diamond Relat. Mater. 19, 131 (2010).

${ }^{41}$ A. C. Ferrari and J. Robertson, Phys. Rev. B 63, 121405(R) (2001). 
${ }^{42}$ D. D. Manchon, A. S. Barker, P. J. Dean, and R. B. Zetterstrom, Solid State Commun. 8, 1227 (1970).

${ }^{43}$ T. Azuhata, T. Sota, K. Suzuki, and S. Nakamura, J. Phys.: Condens. Matter 7, L129 (1995).

${ }^{44}$ H. Harima, J. Phys.: Condens. Matter 14, R967 (2002).

${ }^{45}$ T. Kozawa, T. Kachi, H. Kano, H. Nagase, N. Koide, and K. Manabe, J. Appl. Phys. 77, 4389 (1995).

${ }^{46}$ T. Kozawa, T. Kachi, H. Kano, M. Hashimoto, N. Koide, and K. Manabe, J. Appl. Phys. 75, 1098 (1994).

${ }^{47}$ B. Monemar, Phys. Rev. B 10, 676 (1974).

${ }^{48}$ B. Gil, O. Briot, and R.-L. Aulombard, Phys. Rev. B 52, R17028 (1995).

${ }^{49}$ M. A. Reshchikov and H. Morkoç, J. Appl. Phys. 97, 061301 (2005).

${ }^{50}$ M. Albrecht, S. Christiansen, G. Salvati, C. Zanotti-Fregonara, Y. T. Rebane, Y. G. Shreter, M. Mayer, A. Pelzmann, M. Kamp, K. Ebeling, and M. Bremser, Mater. Res. Soc. Symp. Proc. 468, 293 (1997).

${ }^{51}$ T. F. Huang, A. Marshall, S. Spruytte, and J. S. Harris Jr., J. Cryst. Growth 200, 362 (1999).

${ }^{52}$ V. Kirilyuk, M. Zielinski, P. C. M. Christianen, A. R. A. Zauner, J. L. Weyher, P. R. Hageman, and P. K. Larsen, Mater. Res. Soc. Symp. Proc. 639, G6.23.1 (2001).
${ }^{53}$ A. Dadgar, F. Schulze, M. Wienecke, A. Gadanecz, J. Bläsing, P. Veit, T. Hempel, A. Diez, J. Christen, and A. Krost, New J. Phys. 9, 389 (2007).

${ }^{54}$ J. Furthmüller, J. Hafner, and G. Kresse, Phys. Rev. B 53, 7334 (1996).

${ }^{55}$ M. D. Winn, M. Rassinger, and J. Hafner, Phys. Rev. B 55, 5364 (1997).

${ }^{56}$ T. Frauenheim, U. Stephan, P. Blaudeck, D. Porezag, and H.-G. Busmann, Diamond Relat. Mater. 3, 966 (1994).

${ }^{57}$ Y. Kuang, Y. Wang, N. Lee, A. Badzian, T. Badzian, and T. T. Tsong, Appl. Phys. Lett. 67, 3721 (1995).

${ }^{58}$ M. H. Nazaré and A. J. Neves, Properties, Growth and Applications of Diamond, 1st ed. (INSPEC, London, 2001), Vol. 26.

${ }^{59}$ B. S. Swartzentruber, N. Kitamura, M. G. Lagally, and M. B. Webb, Phys. Rev. B 47, 13432 (1993).

${ }^{60}$ B. S. Swartzentruber, Y. W. Mo, M. B. Webb, and M. G. Lagally, J. Vac. Sci. Technol. A 9, 210 (1990).

${ }^{61}$ M. S. Couto, W. J. P. van Enckevort, B. Wichman, and M. Seal, Appl. Surf. Sci. 62, 263 (1992).

${ }^{62}$ I. V. Markov, Crystal Growth for Beginners, Fundamentals of Nucleation, Crystal Growth and Epitaxy, 2nd ed. (World Scientific, Singapore, 2008).

${ }^{63}$ E. I. Givargizov, M. O. Kliya, V. Melik-Adamyan, A. I. Grebenko, R. C. DeMattei, and R. S. Feigelson, J. Cryst. Growth 112, 758 (1991). 